\title{
A MICROFICÇÃO EM AMÉRICA-LATINA: UM PANORAMA.
}

\author{
Jeimy Espitia Alonso. ${ }^{1}$
}

RESUMO: Este artigo procura indagar os traços e seguir o rastro que algumas formas breves têm deixado na literatura latino-americana numa tentativa de definição, especialmente no sul da América hispana. Tal percurso é feito a partir de alguns escritores e críticos, principalmente hispano-americanos que durante o século XX e entrado o XXI acolhem e exploram as formas breves, mas que até agora não encontraram um lugar autónomo na teoria literária. Assim aparecem denominações várias, tais como: micro-ficção, micro-conto ou micro-relato. Estas expressões breves parecem adquirir uma relação significativa com o território, vinculadas a escritores representativos da região, tanto na criação literária quanto na crítica. Uma das particularidades e potencialidade destas escritas literárias é serem espaços mediadores e geradores de questões e reflexões sobre a linguagem; o autor, a criação literária e o texto, que em outras formas canónicas consideram-se vetadas ou superadas.

PALAVRAS CHAVE: Formas breves; literatura latino-americana; filosofia da linguagem; fragmentos; gênero literário.

RESUMEN: Este artículo pretende indagar sobre los rasgos y seguir los rastros que algunas formas breves han dejado en América latina en un intento por definirlas, especialmente en el sur de Hispanoamérica. Este recorrido es hecho a partir de algunos escritores y críticos, principalmente hispanoamericanos, que durante el siglo XX y entrado el XXI, acogen y exploran las formas breves, que hasta ahora no han encontrado un lugar autónomo en la teoría literaria. De esta forma aparecen denominaciones diversas, tales como: microficción, microcuento o microrelato. Parece que estas expresiones breves adquieren una relación con el territorio, vinculadas a escritores representativos de la región, tanto desde la creación literaria, como desde la crítica. Una de las particularidades y potencialidad de estas escritas literarias es que son espacios mediadores y generadores de cuestiones y reflexiones sobre el lenguaje; el autor, la creación literaria y el texto, que en otras formas canónicas se consideran vetadas o superadas.

PALABRAS CLAVE: Formas breves; literatura latinoamericana; filosofía del lenguaje; fragmentos; género literario.

\section{INTRODUÇÃO}

A microficção não é novidade se pensarmos nela como fragmentos que percorrem e têm transitado pelo mundo literário desde sempre: a frase, o verso, as unidades mínimas. Poderíamos dizer que o mundo literário se compõe de microficções. Em uma nota introdutória de A Conversa infinita. A palavra plural, Maurice Blanchot apresenta a escrita como um acontecimento independente de sistemas designativos sejam eles, novela, conto, poesia, ou ensaio: "Contudo, o

\footnotetext{
${ }^{1}$ Licenciada em língua e literatura castelhana. (USCO) Colômbia. Mestre em literaturas (UFSC). Brasil. Professora substituta (UFAM) Brasil. E-mail: alojespitia@gmail.com
} 
trabalho e a pesquisa literários - mantenhamos esse qualificativo - contribuem para abalar os princípios e as verdades abrigadas pela literatura" (BLANCHOT, 2010, p. 8). A microficção como texto completo traz um desconforto, uma sensação de falta, de incompletude, provocando uma suspeita de transgressão. Assim na escrita e na leitura da microficção a palavra cobra uma transcendência que em outro tipo de textos é mais dissimulada, conforme Blanchot:

Invisivelmente, a escrita é convocada a desfazer o discurso no qual por mais infelizes que nos acreditemos, mantemo-nos, nós que dele dispomos, confortavelmente instalados. Escrever, desse ponto de vista, é a maior violência que existe, pois transgrede a lei, toda lei e sua própria lei (BLANCHOT, 2010, p. 9).

Neste sentido toda escrita é violenta, mas a microficção, pelo menos na cultura ocidental, revela com força o caráter atípico da escrita, do qual fala Barthes:

Só a escritura pode desdobrar-se sem lugar de origem; só ela pode frustrar qualquer regra retórica, qualquer lei de gênero, qualquer arrogância do sistema: a escritura é atópica (...) ela antecipa um estado de práticas de leitura e de escritura, no qual é o desejo que circula, não a dominação" (BARTHES, 2001, p. 138).

A microficção enfrenta-nos nas dicotomias poesia-narrativa, livro-obra, começo-final, mas fora do discurso da diferença positiva que sempre sobrepõe uma na outra. Faz-se necessário pensa-la fora do conceito de gênero independente, definido e fechado. Para Lauro Zavala ${ }^{2}$ o que está em jogo na microficção "é o prazer cúmplice de cada leitura (...). E que talvez atinja a identidade do leitor" (ZAVALA, 2006, p. 56). Aí estaria o acerto de inventividade desta escrita, como uma escrita do desejo, do impulso ou do instante, que consegue atingir o sujeito num ponto em comum: a descontinuidade.

Maurice Blanchot em A conversa infinita se pergunta: "como escrever de tal maneira que a continuidade do movimento da escrita possa deixar intervir fundamentalmente a interrupção como sentido e a ruptura como forma?” (BLANCHOT, 2010, p. 37). A microficção se apresenta inconscientemente como continuidade "que incomoda ao leitor e prejudica nele os hábitos da compreensão normal” (BLANCHOT, 2010, p.37); e isto porque, seguindo o autor de $A$ conversa infinita, a totalidade do real, é justamente "a impossível continuidade do "real" e do “imaginário" (BLANCHOT, 2010, p.37). As formas breves no decorrer do século XX e XXI

\footnotetext{
${ }^{2}$ Lauro Zavala, Ciudad de México (1954). Pesquisador da Universidad Autónoma Metropolitana. Seus temas de interesse se enquadram nos estudos culturais e a pósmodernidade. Em teoria literária tem-se concentrado na narrativa breve.
} 
aparecem como pequenos espaços que multiplicam e reiteram outras literaturas e oralidades; como interrupções de um sistema literário tradicional, sem deixar elas mesmas de fazer parte da tradição.

\title{
TRAÇOS E RASTROS DO BREVE.
}

Comecemos lembrando uma das publicações mais relevantes, como evidência sintomática de um movimento que começa a revelar-se na escrita ficcional e nos estudos da narrativa breve na América Latina. Trata-se do trabalho, em conjunto, de Jorge Luis Borges e Bioy Casares, publicado em 1953, Cuentos breves e extraordinários. Antologia de microficções e fragmentos de diversas culturas e épocas, o texto está composto por pequenas narrações. Eis a breve apresentação dos escritores:

\begin{abstract}
Uno de los muchos agrados que puede suministrar la literatura es el agrado de lo narrativo. Este libro quiere proponer al lector algunos ejemplos del género, ya referentes a sucesos imaginarios, ya a sucesos históricos. Hemos interrogado, para ello, textos de diversas naciones y de diversas épocas, sin omitir las antiguas y generosas fuentes orientales. La anécdota, la parábola y el relato hallan aquí hospitalidad, a condición de ser breves. Lo esencial de lo narrativo está, nos atrevemos a pensar, en estas piezas; lo demás es episodio ilustrativo, análisis psicológico, feliz o inoportuno adorno verbal. Esperamos, lector, que estas páginas te diviertan como nos divirtieron a nosotros. J.L.B. y A.B.C. 29 de julio de $1953 .^{3}$
\end{abstract}

A escolha dos textos, neste caso, está motivada por um gosto pela narrativa essencial, sem "episódios ilustrativos ou análise psicológicas". Estes escritores escolhem textos originalmente breves, mas também desmembram/interferem em outros, trazendo fragmentos: “a peça-parte" é vista como o essencial, o resto como adorno verbal.

Neste sentido, a pesquisadora Italiana Giovanna Minardi ${ }^{4}$ no estudo sobre as microficções de Augusto Monterroso ${ }^{5}$, diz que o fragmento na microficção não mantém o caráter evocativo romântico, mas sim um caráter desestabilizador, sombreado e indagador que desestrutura certezas, remove hierarquias da "monolítica autoridade do sistema total" (MINARDI, 2013, p. 3), gerando, portanto, novos vínculos e descontinuidades. Eis a relevância da publicação de Casares e Borges para o breve na narrativa. Por outro lado, a antologia inclui textos dos próprios autores

\footnotetext{
${ }^{3}$ Texto digitalizado, disponível online em: https://treseso.files.wordpress.com/2010/11/jorge-luis-borges-y-a-bioycasares-cuentos-breves-y-extraordinarios.pdf. Sem numeração de página.

${ }^{4}$ Pesquisadora italiana, especialista no conto hispano-americano.

${ }^{5}$ MINARDI, Giovanna. Los microrrelatos de Augusto Monterroso: uma lectura anticanónica de la fábula. Artigo on-line. Em: http://orillas.cab.unipd.it/orillas/articoli/numero_2/05Minardi_rumbos.pdf
} 
(Borges e Casares), mas assinados com pseudônimos, confundindo escritor-tradutor e jogando com a ideia de tradução: vista como outra escrita e não só uma "cópia".

A mistura de formas neste texto coloca questões como a escrita circular, o palimpsesto, a ideia de livro, a autoria, e também sobre a forma de fazer história da literatura. Não se trata, então, de catalogar uma forma literária, pois por trás da microficção há um movimento que transcende os juízos teóricos classificatórios e fechados.

Pamapa Arám, professora e pesquisadora argentina e quem contextualiza a obra borgeana no fantástico - e lembremos, guardando as proporções, o favoritismo de Borges pela forma curta - vê-la dentro de um movimento poético e político, na medida em que intervém no sistema artístico dos gêneros narrativos vigentes no momento. Esses gêneros, por sua vez, são intermediados pelas condições da época como, por exemplo, a presença de importantes editoras e suas múltiplas estratégias de publicação (novos formatos que incorporam traduções, antologias e coleções, movimento promovido pela modernização de Buenos Aires e o avanço do jornalismo cultural). Acrescente-se o impacto da arte cinematográfica (por sua natureza mais fragmentária), na formação de um imaginário urbano e na criação das obras de escritores como Jorge L. Borges, Bioy Casares, Horácio Quiroga e Roberto Arlt (ARÁM, 2000). ${ }^{6}$

Arám pensa este movimento particularmente na região rio-platense, e este caminho coincide com outro filho da mesma agitação poética da época, Julio Cortázar, que, desde sua experiência de leitor e escritor, também traça algumas características que marcarão a literatura ficcional nessa mesma região. Essas caraterísticas nos interessam na medida em que podemos lêlas como antecedentes da narrativa breve, que estoura, pelo menos na alvorada do breve, particularmente no Cone Sul e mais ainda na região do Rio da prata.

Nas conferências “O estado atual da literatura na América Hispânica” (1978), “A literatura latino-americana à luz da história contemporânea" (1980) e "Realidade e literatura na América-latina" (1980), textos reunidos em sua Obra crítica, Julio Cortázar coloca a questão do estado da literatura, especialmente na Argentina e seus vizinhos. Da mesma forma que Arám, entre outros escritores e críticos, Cortázar encontra a literatura da América Latina configurada nos termos do fantástico. A respeito disso, a pesquisadora Miriam Di Gerónimo em seu estudo sobre Julio Cortázar Narrar por knock-out. La poética del cuento de Julio Cortázar, diz que o autor, da mesma forma que Borges, não destrói a realidade, mas quebra a lógica discursiva da modernidade. Podemos então considerar estes critérios para pensar a microficção e assim ver

\footnotetext{
${ }^{6}$ ARÁM, Pampa. La rigurosa magia del fantástico borgeano. Universidade Nacional de Córdoba, Argentina. Texto on-line, sem paginação. http://pendientedemigracion.ucm.es/info/especulo/numero15/fan_borg.html
} 
como este recurso já tem em si a dimensão fantástica como fator que lentamente leva ao leitor e ao escritor a dar as costas a uma realidade normatizada e, por conseguinte, a desestabilizá-la.

No percurso da leitura das conferências, vemos que uma das caraterísticas colocadas em primeiro lugar é justamente a marginalidade que tinha o fantástico na literatura inglesa e norteamericana, que via a realidade como a "terra prometida", enquanto que para os latinoamericanos, segundo Cortázar, já haveria um convívio com o fantástico, o mágico, o espiritual, o maravilhoso ${ }^{7}$. Assim, a realidade não teria privilégios, isto não em razão de uma particular condição territorial, mas pela sensibilidade mental diante destes elementos que, além de sua efetiva presença, nos oferecem brevemente irrupções rápidas do fantástico: "Na maioria dos casos tal irrupção do desconhecido não passa de uma sensação terrivelmente breve e fugaz de que existe um significado, uma porta aberta para uma realidade que se confere a nós, mas tristemente, não somos capazes de aprender”. (CORTÁZAR, 2001, p. 90).

Assim, o leitor sensível identificaria claramente o "estranho" não como uma imagem, mas como um sentimento. Consequentemente o entendimento é de outro tipo, dificultando em grande medida a tradução dessa situação, isto é, transformá-la em termos lógico-discursivos, gerando a necessidade dos escritores de "explicar" aquela reverberação "como uma força que não reside tão somente na qualidade narrativa, mas também num impulso que parece proceder de regiões escuras da psique" (CORTÁZAR, 2001, p. 193).

Cortázar pensará a literatura da América Latina como um eterno questionar-se, uma literatura que nos oferece perguntas, portas que conduzem a outras portas e novas perspectivas do real, justamente pelo seu caráter descontínuo.

Ainda, segundo Cortázar, a própria influência do gótico clássico sobre o fantástico no novo mundo, e especificamente no Cone Sul, teria tomado outros rumos, por exemplo, o de uma engrenagem do acaso. Críticos como Silviano Santiago, que pensa o discurso latino-americano a partir da incorporação no Brasil e na América-Latina do pensamento europeu, vê-lo, em geral, como:

Entre o sacrifício e o jogo, entre a prisão e a transgressão, entre a submissão ao código e a agressão, entre a obediência e a rebelião, entre a assimilação e a expressão - Ali nesse lugar aparentemente vazio, seu templo e seu lugar de clandestinidade, ali, se realiza o ritual antropófago da literatura latino-americana (SANTIAGO, 2000, p. 26).

\footnotetext{
${ }^{7}$ Neste artigo não poderíamos esclarecer, por espaço, as diferenças entre o realismo mágico, real maravilhoso e o fantástico. Porém, é importante sublinhar que o comentário do escritor na conferência aqui referida tem um caráter informal, pois ele deixa clara sua posição de leitor e não de crítico literário. Desta forma a relação do mágico, maravilhoso e fantástico é uma relação geral com o território de especulação que foi o continente americano desde sua descoberta: a terra do mito, do fantástico, do desconhecido, o novo mundo onde foram possíveis o El dorado, as Amazonas...
} 
Podemos situar a microficção num movimento antropofágico entre o gótico e o fantástico na América Latina, pois ela vai tomando lugar nesses entre-lugares, na clandestinidade. Vejamos uma microficção de Anderson Imbert na qual lemos o entre lugar, neste caso entre o humano e o divino, entre o segredo e a violenta busca do conhecimento e entre as mãos do homem morto que se convertem nas asas do anjo humilhado (imagens essas que nos sugerem diversas outras). Por que não pensar na ditadura? $\mathrm{Na}$ tortura? $\mathrm{Na}$ escrita como transgressão lida nas mãos violentamente arrancadas do corpo, talvez numa imagem poética cristã do sacrifício pela verdade? Imbert nos apresenta uma realidade na qual acreditamos; a escola, o professor, os alunos e, por conseguinte, a irrupção de outro real. Imagens poéticas e comuns que se juntam para não se separar.

Las manos - Enrique Anderson Imbert (1910-2000)

En la sala de profesores estábamos comentando las rarezas de Céspedes, el nuevo colega, cuando alguien, desde la ventana, nos avisó que ya venía por el jardín. Nos callamos, con las caras atentas. Se abrió la puerta y por un instante la luz plateada de la tarde flameó sobre los hombros de Céspedes. Saludó con una inclinación de cabeza y fue a firmar. Entonces vimos que levantaba dos manos erizadas de espinas. Trazó un garabato y sin mirar a nadie salió rápidamente. Días más tarde se nos apareció en medio de la sala, sin darnos tiempo a interrumpir nuestra conversación. Se acercó al escritorio y al tomar el lapicero mostró las manos inflamadas por las ampollas del fuego. Otro día -ya los profesores nos habíamos acostumbrado a vigilárselas- se las vimos mordidas, desgarradas. Firmó como pudo y se fue. Céspedes era como el viento: si le hablábamos se nos iba con la voz. Pasó una semana. Supimos que no había dado clases. Nadie sabía dónde estaba. En su casa no había dormido. En las primeras horas de la mañana del sábado una alumna lo encontró tendido entre los rododendros del jardín. Estaba muerto, sin manos. Se las habían arrancado de un tirón. Se averiguó que Céspedes había andado a la caza del arcángel sin alas que conoce todos los secretos. Quizá Céspedes estuvo a punto de cazarlo en sucesivas ocasiones. Si fue así, el arcángel debió de escabullirse en sucesivas ocasiones. Probablemente el arcángel creó la primera vez un zarzal, la segunda una hoguera, la tercera una bestia de fauces abiertas, y cada vez se precipitó en sus propias creaciones arrastrando las manos de Céspedes hasta que él, de dolor, tuvo que soltar. Quizá la última vez Céspedes aguantó la pena y no soltó; y el arcángel sin alas volvió humillado a su reino, con manos de hombre prendidas para siempre a sus espaldas celestes. ¡Vaya a saber! ${ }^{8}$

Em "Pulsión" de Pia Barros, as imagens se fundem ainda mais:

El viene caminando por mi grito, él corre ya arrancado por mi grito, él se arrastra obsesionado porque no sabe que repta por la lengua de mi grito. Y lo espero (BARROS, 2006, p. 92).

\footnotetext{
${ }^{8}$ Texto disponível on-line.
} 
A microficção em nosso continente se localiza às margens de um movimento em que a palavra torna-se texto(s). Não se ajusta a nenhum discurso específico de gênero, pelo que aparecerá como uma reverberação "des-generada" (ROJO, 2009), dessa forma, mais como experiência criadora do que como forma criada. Dolores Koch em seus estudos dirá que esta escrita mínima é subversiva e perturbadora, pois, nela se mobilizam relações diversas com a palavra que se desprende a saltos. Palavra descontínua, instante quase onírico, lugar em que, para Cortázar, temos mais em comum uns com os outros do que quando estamos acordados.

\section{SOBRE O TERMO.}

Evidencia-se certa perturbação quando se pretende mapear e registrar esta forma literária. Não obstante, existem trabalhos que objetivam esclarecer os termos microficção, microrrelato e microtexto, por serem os mais abrangentes e usados na denominação do breve. Esses trabalhos coincidem claramente em ressaltar a brevidade como característica comum da microficção. Como se verá, vários(as) dos(as) pesquisadores(as) aqui citados(as) expõem as mesmas características sobre a microficção, porém associando-a com diferentes nomes. Em outros casos, usaram o mesmo nome para mencionar diversas caraterísticas sobre estas formas curtas. Esses entrecruzamentos refletem a dificuldade que há em classificar definitivamente o microficcional. Aqui revisaremos algumas dessas pesquisas numa leitura da microficção que reivindica sua estrutura móvel, inapreensível e camaleônica.

Partindo do estudo que faz David Lagmanovich, crítico e também microficcionista argentino, o microrrelato faria parte da microficção que, por sua vez, é um microtexto. Mas não todo microtexto é microficção e não toda microficção é microrrelato. Vejamos algumas considerações a partir de Lagmanovich.

A microficção seria qualquer texto brevíssimo de caráter ficcional que não necessariamente conta uma história estruturada com personagens, começo ou final. Assim, muitos textos breves pertencem à microficção em geral, isto é: poema em prosa, vinheta, piada, aforismo, anedota. Tanto o microconto quanto o microrrelato interagem com estas outras formas mencionadas. Nesse sentido, para que um microtexto seja uma microficção, é necessário que contenha uma função estética, e quando a microficção conta uma história então teríamos ai um microrrelato, que por seu caráter narrativo explícito se localizaria no ciclo tradicional da narrativa, isto é: romance - novela - conto - microrrelato (LAGMANOVICH, 2006, p. 25-26). Por outro lado, a microficção pode-se movimentar nestas regiões sem ser determinada por elas, 
neste sentido, a microficção aparece como elemento primário que poderia ser contornado, seja como microconto ou como microrrelato.

Violeta Rojo ${ }^{9}$ vê a microficção como um (outro) gênero proteico e multiforme. Os microrrelatos e microcontos compartilham, não só a brevidade, mas também a independência textual. No entanto as microficções podem fazer parte de um conjunto narrativo, por exemplo, textos compostos fragmentariamente, como em Historia de cronopios y de famas (1963) de Julio Cortázar, ou como em Eduardo Galeano ${ }^{10}$, Patas arriba: a escuela del mundo al revés (1998), Fenómenos de circo de A. María Shua (2010). No caso do Brasil, podemos pensar nas Memórias sentimentais de João Miramar, de Oswald de Andrade.

Encontramos também microrrelatos que, apesar de independentes, têm um fío quase invisível enlaçando-os. Esta forma é denominada por Zavala como fractais, isto é, uma existência de um todo formado por fragmentos que embora possam ser lidos no conjunto podem ser independentes. Por outro lado encontramos também, como na antologia de Bioy Casares e Borges, microrrelatos que, ainda que juntos num mesmo texto, mantêm independência narrativa total.

Para Dolores Koch o microconto deve ter uma exposição, um enredo e um desenlace:

Debido a los recursos estilísticos empleados para lograr la brevedad, algunas de estas etapas sólo se sugieren. La exposición nos dará una idea de la ubicación del narrador o del personaje, esto es, su identidad, localidad y tiempo histórico. El nudo o el conflicto apuntará a su situación o disyuntiva, y el desenlace resolverá esa situación por medio de un suceso o acción concreta. ${ }^{11}$

Vejamos um exemplo que a mesma Koch oferece de microconto:

El juicio (Gabriel Jiménez Emán- México)

Se encontraba en medio del tribunal, todas las miradas de los jueces clavadas negramente en él. Esperaba la sentencia. - Lo condeno a vivir para siempre dijo uno de los esqueletos.

\footnotetext{
${ }^{9}$ Doutora, professora e pesquisadora. Universidade Central de Venezuela. Especialista na forma breve.

${ }^{10}$ Escritor Uruguaio, mais conhecido pelos leitores em As veias abertas da América-latina, quem hoje é um dos mais sucedidos escritos de microrrelatos, pelo menos na indústria editorial e na sua recepção. Galeano abre com um dos seus microtextos o último disco musical do conhecido, pelo público hispano-americano, grupo porto-riquense Calle 13, o microtexto num fundo musical é lido pelo escritor. Faço este comentário aproposito dos alcances do breve que se camufla para trafegar além do livro.

${ }^{11} \mathrm{KOCH}$, Dolores. Retorno al mirorrelato: algunas consideraciones. Em El cuento en red. Revista literaria de ficción breve. Disponível em: http://cuentoenred.xoc.uam.mx/presentacion.html. "Devido á os recursos estilísticos usados para conseguir a brevidade algumas de estas etapas são só sugeridas. A exposição nos dará uma ideia da localização do narrador, ou do personagem, isto é sua identidade, lugar e tempo histórico. O enredo o conflito apontara para sua situação ou disjuntiva, e o desenlace resolvera essa situação por meio de um acontecimento ou ação concreta". (tradução própria).
} 
Acrescento ainda o de Ramón Gómez de la Serna, escritor espanhol que teve uma grande influência na poesia e na narrativa breve rio-platense com suas greguerías ${ }^{12}$ para ver a estrutura do microconto desde a perspectiva de Koch, quando o desenlace acontece numa ação concreta:

\begin{abstract}
El ciego bellísimo
Aquella mujer repulsiva y fea se casó con el ciego de una belleza leonardesca. No le dejaba a solas con ninguna mujer y como aquel ciego no pudo tocar ningún otro rostro de mujer que el de la suya, no tenía idea de la medida. El lazarillo tenía órdenes severas de no dejar que se acercase a él ninguna mujer y él, sabiendo lo celosa que era la mujer, huía de todas. Un día en un museo de escultura, acaricio el rostro de una Venus y, asombrado e repugnado, cuando llegó a casa estranguló a su mujer, indignado por el engaño irreparable (DE LA SERNA, 2005, p. 72).
\end{abstract}

Jamime Alejando Rodríguez ${ }^{13}$ explica que o microconto seria a simplificação da estrutura canônica da narração. Tal simplificação se localiza somente na extensão do texto, pois os jogos internos desta narrativa abrigam multiplicidade de elementos que, antes mesmo de serem simples, fazem deste um texto irreverente: "A la impertinencia predicativa se le superpone así, en palabras de Paulo Ricoeur, una pertenencia profunda al mundo de la vida... Y ese es, precisamente, el poder de la ficción: la des-automatización de la percepción cotidiana, la recuperación de los sentidos profundos de la realidad" (RODRIGUEZ,2004,p.10). Esta impertinência, presente em todo texto ficcional, por assim dizer, apresenta-se intensificada nas microficções, sendo que a microficção agrega uma impertinência maior, pois o seu desfecho não se apresenta em um fato concreto, como no caso dos microrrelatos citados acima.

Seguindo a Koch o microrrelato dependerá de uma ideia insinuada, já os microcontos, conforme citados, terminam com uma condenação (fechamento): morte/assassinato. Vejamos agora um microrrelato para ilustrar a diferença fundamental entre estas formas breves:

\title{
Pequeños cuerpos. Triunfo Arciniegas (Colômbia)
}

Los niños entraron a la casa y destrozaron las jaulas. La mujer encontró los cuerpos muertos y enloqueció. Los pájaros no regresaron (ACINIEGAS, 2010, p. 38).

O que aconteceu aqui? Podemos levantar várias hipóteses sobre o porquê ou como morreram as crianças, mas o acontecimento depende das ideias que o leitor constrói; o desfecho,

\footnotetext{
12 "Su obra [como] recogedora de la emoción átomo, de la vida fragmentaria, en los mil aspectos de la hora viva y multiforme" Comentario sobre as greguerías de La Serna, do crítico Argentino Juan M Filartigas. Em Boletin Ramón, n 3. otono 2004, 4. Disponivel on-line: http://www.ramongomezdelaserna.net/BR3-PDF.PDF

${ }^{13}$ Doutor e professor de literatura, pesquisador da Pontificia Universidad Javeriana de Colômbia.
} 
se houver, acontece na leitura. Entretanto, no microconto, o que se passa se dá no mundo exterior, pois, no próprio texto há a descrição do desfecho.

De outra parte, Lauro Zavala ${ }^{14}$ aponta para as diferenças entre microconto e microficção ${ }^{15}$ (ele as chama minicuento e minificción). Para ele, o microconto teria um caráter tradicional, sendo uma narração completa e autossuficiente, enquanto que a microficção teria um caráter essencialmente experimental com elementos modernos ou pós-modernos; isto é o fragmentário como qualidade moderna e o fractal como pós-moderna: "la minificción siempre surge como consecuencia de un acto de relectura irónica o paradójica de convenciones textuales, ya sean genéricas o ideológicas (o ambas)" 16

Violeta Rojo se decide pelo termo microconto para falar da microficção em geral, ainda que em seu trabalho reconheça que estamos falando de um gênero literário novo e diferente do conto, do romance, da poesia e do ensaio, que precisa ser visto sob lentes próprias. Para Rojo o microconto é um híbrido, no qual são importantes os elementos humorísticos, irônicos, intertextuais e meta-ficcionais. São justamente esses elementos que nos permitem questionar o uso que faz a autora do termo microconto, pois as formas curtas não seriam unicamente caminhos para a redução do conto.

No Brasil, Heloisa Buarque ${ }^{17}$ se mostra consciente da existência da microficção no âmbito literário brasileiro, e da tarefa imediata que se coloca: "a crítica tem que correr atrás do seu objeto porque este está andando muito rápido e principalmente agora ele está andando mais rápido ainda" (BUARQUE, apud, DE SOUZA RODRIGUEZ, 2012, p. 73). Sobre as formas breves no Brasil podemos ver seus rastros em textos como Ficção brasileira contemporânea (2009) de Karl E. Schollhammer, em que se analisa a escrita breve e fragmentada como a manifestação de certa urgência relacionada com a impossibilidade de captar as realidades. Urgência da palavra que emerge de espaços emotivos, rápidos, e desta maneira o breve procura abordar contextos inteligíveis, acontecimentos que não cabem mais em vastos discursos. Esta escrita se situa na cultura do ruído, da onomatopeia, dos sons, dos cliques, dos flashes, da gritaria cotidiana e dos gestos. Marcelino Freire, citado por Schollhammer, comenta respeito à brevidade da microficção: "De fato, escrevo curto e, sobre tudo, grosso, escrevo com urgência. Escrevo para me vingar. E esta vingança tem pressa. Não tenho tempo para nhenhenhéns. Quero logo dizer o que quero e ir embora" (FREIRE, apud, SCHOLLHAMMER, 2009, p. 10).

\footnotetext{
${ }^{14}$ Professor e pesquisador mexicano, da Universidade Autónoma Metropolitana de Xochimilco. Suas linhas de pesquisa são: estudos sobre a Ironia, a metaficção e microrrelato, e cinema.

${ }_{16}^{15}$ Enquanto Koch pensa as relações microconto/microrelato, Zavala vai pensa-las entre microconto/microficção.

16 ZAVALA, Lauro. Para analisar la minificción. Artigo sem paginação, disponivel on-line em: http://www.academia.edu/1331417/Para_analizar_la minificcion\#

${ }^{17}$ Escritora, pesquisadora e professora da UFRJ.
} 
Esta pressa não é só a pressa do mundo moderno onde o tempo vale ouro, ou da informação, das tecnologias; mas de um discurso impraticável, como na microficção "Golpe" de Pia Barros, em que a dor da guerra pela ditadura se expressa com a mesma urgência das crianças quando querem saber tudo:

Golpe. Mamá, dijo el niño, ¿qué es un golpe? Algo que duele muchísimo y deja amoratado el lugar donde te dio. El niño fue hasta la puerta de casa. Todo el país que le cupo en la mirada tenía un tinte violáceo (BARROS, 2006, p. 31).

Se pelo lado da crítica ainda é muito amplo o campo de conceitualização da microficção, pelo da escrita, embora a questão também não apresente definições claras e estruturas visíveis de imediato, alguns escritores, ao serem questionados sobre a forma dessa escrita, vão traçando caminhos a partir dos quais podemos empreender o percurso crítico do microficcional. João Gilberto Noll, por exemplo, numa entrevista sobre seu trabalho Mínimos, múltiplos, comuns fala de "romances inteiros, minúsculos" e "milimétricos surtos ficcionais", "instantes ficcionais". Noll associa a escrita breve com "a consagração do instante" de Octavio Paz no Arco e a lira: "Ou seja microcontos poemáticos em que você suspende por alguns momentos o fluxo normal de uma narrativa a principio mais extensa e que parece correr pelo livro todo" (NOLL.Apud.VEJMELKA, 2009, p. 131). Marcel Vejmelka, nos seus comentários sobre as definições dadas por Noll, dirá que o autor está fugindo das associações conceituais que o breve tem na forte tradição do Sul do Prata:

Ao contrário Noll estabelece uma referência dupla para seu projeto: a poesia para condensação do instante e, no sentido proposto por Octavio Paz, como "consagração" e isolamento do fluxo do tempo secular e histórico, o qual Noll combina com a sua poética da percepção repentinamente interrompida ou imposta da realidade (VEJMELKA, 2009, p. 131).

Embora, segundo Veljmeka, Noll faça uma tentativa de fuga, sua própria tentativa o leva a se corresponder com o movimento metafísico ficcional que ampara as microficções na América Latina e que Pampa Arán situa justamente na escrita desenvolvida na região rioplatense. Mas é interessante ver que o escritor não quer submeter-se ao enquadramento dentro das denominações da narrativa breve que claramente ainda remetem a América Hispânica. Violeta Rojo cria o termo des-generado para felicidade da crítica, que vê na microficção a possibilidade de uma abordagem diferente, quase um jogo a partir desta literatura "desgenerada". E é por esse aminho que muitos escritores preferem ler sua incursão no breve. 
Dalton Trevisan, como vários mencionados anteriormente, faz um caminho inverso ao que tradicionalmente se pensa relacionado aos escritores reconhecidos (profissionais). Por um lado está a permanente reescrita dos próprios textos, por outro, a brevidade que tal reescrita leva consigo, como num aperfeiçoamento:

Para escrever o menor dos contos a vida inteira é curta. Nunca termino uma historia. Cada vez que a releio eu a reescrevo (e, segundo os críticos, para pior). Há o preconceito que depois do conto, você deve escrever novela e ao final romance. Meu caminho será o do conto para o soneto e dele para o haicai (TREVISAN, Apud, SHOLLHAMMER, 2009, p. 97).

Vejamos como este posicionamento se encontra com o do poeta dominicano Manuel Del Cabral (1907-1999), que também se aproxima da microficção com textos compostos de narrativas breves: "O futuro da novela é o conto, e o porvir do conto é a parábola, e se a evolução não se detém - o que duvido - a síntese do romance, do conto e da parábola é inevitavelmente o aforismo"18 (LAGMANOVICH, apud, DEL CABRAL, 2006, p. 250). Com isto vemos um movimento onde confluem, por um lado, o esgotamento das grandes narrativas, por outro, a volta para uma tradição oral. De novo no entre-lugar entre a volta à tradição do narrador e sua impossibilidade, a microficção alimenta-se das possibilidades e das impossibilidades na criação de espaços literários descontínuos.

111 ais de Trevisan é um texto que contém 111 microtextos numerados e acompanhados de ilustrações brancas e pretas, como que rascunhos em lápis. Esses são "ais" breves e contínuos dos casais, da vida corriqueira fragmentada em pequenas queixas, confissões, acusações, exclamações, enfim, ais! Revelados à maneira de diálogos e meditações tomadas pela ironia, despojados de qualquer peso cerimonial ou formal, às vezes cínicos:

61 - Você conhece o antigo rótulo da Emulsão de Scott? Assim eu me sinto. Casada... Não, não. Cansada, isso. Curvada, sim. Ao peso do eterno bacalhau Também: nas costas (TERVISAN, 2000, p. 67).

80 Do ultimo verão, no tronco da árvore, a casca vazia de uma cigarra: ouça o canto (TREVISAN, 2000, p. 86).

A poesia como experiência da linguagem tem um papel fundamental na formação da microficção. Di Gerónimo localiza justamente nesse ponto a narrativa cortazariana, que conta com algumas caraterísticas da poesia como: a origem num repentino estranhamento,

\footnotetext{
${ }^{18}$ Tradução própria.
} 
inconsciente, a estrutura esférica preexistente ao ato da escrita, a tensão, o ritmo; o imprevisto dentro de parâmetros previstos (DI GERÓNIMO, 2004, p. 173). Não só em Cortázar podemos fazer estas associações. João Gilberto Noll, em sua proposta teórica para Mínimos, múltiplos, comuns, coincide com o manifesto da revista colombiana Zona ${ }^{19}$, citado por Francisca Noregol a respeito do microconto:

Concebido como um híbrido, um cruzamento entre o relato e o poema (...), o microconto está chamado a liberar as palavras de toda atadura. E devolver-lhes seu poder magico, esse poder de escandalizar-nos (...). Não se deixa dominar nem emoldurar e por isto estende a ponte à poesia quando tentam aplicar-lhe normas académicas ${ }^{20}$ (NOREGOL, 2011, p. 2).

Finalmente, nessas considerações, temos que mencionar duas pesquisadoras que aportam desde o terreno teórico uma imagem, a nosso ver, fantástica, da microficção como "uma máquina de/para pensar". Graciela Tomassini e Stella Maris Colombo ${ }^{21}$ trazem esta imagem que também remete à máquina de pensar de Raimundo Lulio, comentada por Borges (1937), em que uma sorte de montagem combina letras e palavras para consolidar um sistema filosófico universal. Para Borges, tal aparelho teria mais valor em termos literários e poéticos do que investigativos e filosóficos. Referindo-se a esta imagem, as pesquisadoras contemplam o caráter disparador e combinatório de pensamentos que é a microficção:

Es sabido que toda ficción, en tanto arte combinatoria, lo es; pero de nuestra parte consideramos que esa característica puede predicarse aún con más razón acerca de la ficción brevísima, ya que en sus manifestaciones más creativas y depuradas concentra y sintetiza en un mínimo despliegue textual una perspectiva diferente sobre el mundo, toda vez que saca al lenguaje de sus goznes habituales e incita al lector a abandonar esquemas perceptivos rutinarios y anquilosados ${ }^{22}$ (TOMASSINI; COLOMBO, p. 36).

O que conhecemos como pós-estruturalismo veicula uma série de discussões em torno da linguagem, procura não desestruturar, mas analisar e rever a estrutura não como um sistema

\footnotetext{
${ }^{19}$ Até agora não consegui informação desta revista, porém é citada por Francisca Noregol que à vez cita-a de Edmundo Valadés. A primeira teórica da microficção e o segundo teórico e microficcionista.

20 “Concebido como un híbrido, un cruce entre el relato y el poema (...), el minicuento está llamado a liberar las palabras de toda atadura. Y a devolverles su poder mágico, ese poder de escandalizarnos (...). No se deja dominar ni encasillar y por eso tiende su puente a la poesía cuando le intentan aplicar normas académicas"

${ }^{21}$ Pesquisadoras da Universidade Nacinal de Rosario (Argentina).

${ }^{22}$ Sabe-se que toda ficção é enquanto arte combinatória, mas da nossa parte, consideramos que essa caraterística se pode predicar ainda com mais razão sobre a ficção brevíssima, pois em suas manifestações mais criativas e depuradas concentra e sintetiza um desdobramento textual, uma perspectiva diferente sobre o mundo uma vez que saca a linguagem de suas bisagras habituais e incita á o leitor a abandonar esquemas perceptivos rotineiros e anquilosados. (tradição propria). Texto completo on-line em: http://148.206.107.15/biblioteca_digital/articulos/10644-9358bnh.pdf
} 
estático, mas sempre mutante e móvel. Assim, as análises que começaram estudando a língua como sistema independente, se deslocam para pensar e questionar a ideia de sujeito e das instituições que o assumem como tal, seja a escola, a universidade, o Estado, a prisão, a família, a fábrica, as ciências, a filosofia. Neste movimento se pensa a palavra e outras formas de escrita e leitura, do texto e da obra. É neste contexto que, a partir da análise de diversos âmbitos das sociedades ocidentais, se prepara o terreno para pensar a literatura em outras esferas, ou na mistura das mesmas (política, econômica e cultural). Neste terreno surgem várias das reflexões sobre microtextos legitimando sua abordagem crítica na atualidade.

O mundo microficcional leva-nos a pensar em várias relações, como sua transcendência e, paradoxalmente, marginalidade no mundo literário, por parecer um movimento mais próprio da linguagem em permanente questionamento do que de práticas ligadas a discursos literários determinados. A microficção questiona o espaço, o tempo, a história, coloca um vazio que vai além do espaço da folha em branco, como silêncios, textos, imagens, palavras ausentes. Abarcada totalmente pelo olho do leitor, mas inacabada nos seus sentidos mais profundos, ali está camuflada entre narrativa, poesia e filosofia.

Pensemos que a maioria dos medos na cultura ocidental está fundada na morte como destino incerto, teme-se o desaparecimento físico terreno. Assusta-nos a ausência do outro como extravio do eu; apreendemos como males iminentes: o esquecimento, o nada, o silêncio. É aqui que a palavra se revela como angústia pela morte irrealizável. A palavra, situando-se nos interditos da cultura, dá lugar à transgressão. Bataille em $O$ Erotismo diz: "Que seriamos nós sem a linguagem? Ela nos fez o que nós somos. Só ela revela, em última instância, o momento soberano em que ela não existe mais (...)" (BATAILLE, 1987, p. 235). O mesmo autor em $A$ literatura e o mal identifica a sua geração como tumultuosa (depois da primeira guerra mundial), pois havia "um sentimento que transbordava. A literatura sufocava em seus limites, parecia que ela continha em si uma revolução" (BATAILLE, 1989, p. 8).

Assim, a literatura na possibilidade que lhe é dada na dimensão ficcional e fantástica se desdobra para pensar a impossibilidade de experiência no real. Nestes espaços literários a palavra está à procura de sua suspensão. É possível situar aqui a microficção, escrita que se configura num artifício de transgressão de si própria. Deparamo-nos com a lúcida e reiterada impotência da linguagem por não corresponder às lógicas do bem, da lei e da razão. Eis uma microficção de Ana Maria Shua, para exemplificar está "impotência":

Dudoso circo. Usted cree estar en un circo pero tiene dudas, busca pruebas. La osa tiene la cara de su madre, la palabra acróbata, sin dejar de ser puro sonido, 
está hecha de letras rojas y se puede comer. Usted, que sin embargo no es una mujer, está amamantando un tigre pequeño, que sin embrago, no es un bebé. Usted hace lo posible por despertarse con el sonido de la orquestra, pero la música le resulta hipnótica, asfixiante. Con las manos agarrotadas por el sueño usted logra apartar la almohada de la nariz y ahora respira mejor. Nada de esto prueba que usted no este realmente en un circo. Para estar seguro tendrá que despertarse, mirar a su alrededor, asegurarse de que no ha desembocado en otro sueño. Y, sin embargo (SHUA, 2011, p. 11) ${ }^{23}$.

\section{CONSIDERAÇÕES FINAIS}

Como visto, é possível pensar em algumas classificações das formas brevíssimas, embora, finalmente, careçam “de carteira de identidade” (ROJO, 2009, p.37). Pensemos no camaleão como alegoria da microficção, que se camufla, que interfere passando de uma forma para outra, entre épocas e tempos; lugares e palavras que permanecem interrompidas. E os melhores indícios sobre sua natureza se dão nela mesma, como na microficção de Paco Conde, textos que surgiram camuflados como correios eletrônicos ${ }^{24}$, e-mails dirigidos aos colegas de trabalho, mensagens que não comunicavam nada além de si mesmas, palavras:

Conjuntados. Sus ojos hacían juego con su camisa. Su camisa hacía juego con sus zapatos. Sus zapatos hacían juego con su bolso. Su bolso hacía juego con su falda. Su falda hacía juego con el cielo. El cielo hacía juego con su pelo. Su pelo hacía juego con el aire, el aire hacía juego con sus llaves. Sus llaves hacían juego con su casa. Su casa hacía juego con su sofá. Su sofá hacía juego con su jardín. Su jardín hacía juego con su camaleón. Su camaleón hacía juego con su nevera. Su nevera hacía juego con sus platos. Sus platos hacían juego con sus cubiertos. Sus cubiertos hacían juego com. Oops!!! El camaleón cambió de color. $^{25}$

\footnotetext{
${ }^{23}$ Circo duvidoso Você, acredita estar em um circo, mas duvida, procura provas, a ursa tem o rosto de sua mãe, a palavra acrobata, sem deixar de ser puro som, é feita de letras vermelhas e pode-se comer. Você, embora não seja uma mulher, está amamentando um tigre pequeno, embora não seja um bebé. Você faz o possível por acordar com o som da orquestra, mas a música resulta-lhe hipnótica, asfixiante. Com as mãos intumescidas pelo sonho, você consegue afastar o travesseiro do nariz, e agora respira melhor. Nada disso prova que você não esteja realmente em um circo. Para estar seguro terá que acordar olhar ao seu redor, ter certeza que não há desembocado em outro sonho. E, no entanto. (tradução própria).

${ }^{24}$ Paco Conde é um publicitário espanhol, que escreve e-mail a seus colegas, e depois recopilará para publicar em um pequeno livro ilustrado chamado simplesmente Microrrelatos.

${ }^{25}$ CONDE, Paco. Conjuntados. Seus olhos combinavam com sua camisa. Sua camisa combinava com seus sapatos, Seus sapatos combinavam com sua bolsa. Sua bolsa combinava com sua saia. Sua saia combinava com o céu. O céu combinava com seus cabelos. Seus cabelos combinavam com o ar. O ar combinava com suas chaves. Suas chaves combinavam com sua casa. Sua casa combinava com seu sofá. Seu sofá combinava com seu jardim. Seu jardim combinava com seu camaleão. Seu camaleão combinava com sua geladeira. Sua geladeira combinava com seus pratos. Seus pratos combinavam com seus talheres. Seus talheres combinavam com. Oops!!! O camaleão mudou de cor. Recurso disponível on-line,
} http://issuu.com/alvaro_sobrino/docs/microrrelatos\#embed 
Infiltrado, o camaleão nos confunde porque se camufla ou compeli o outro num movimento de inter-camuflagem, sem poder distinguir camuflado e território: "Seu jardim combinava com seu camaleão", e nesse movimento não é o camaleão que se adapta. O pequeno animal, lento, com aparência de tédio, obriga o jardim a se transformar; e, num gesto rápido, num ato como de caça, acontece o deslocamento veloz e certeiro. Como o camaleão, a microficção se camufla num gesto de sobrevivência, que hoje parece estar sendo descoberta ou capturada.

Por conseguinte, a microficção carrega consigo um movimento de épocas, uma agitação construída nas sobrevivências de outras escritas, tempos, formas, estilos. A microficção aparece como um espectro literário, uma presença diluída e meio apagada, mas presente. E, como já dizemos anteriormente, cada vez mais presente e menos espectral na medida em que se procura definir sua estrutura. Segundo Rosalba Campra ${ }^{26}$, escritora também de microficções, elas podem ser chamadas de microromances, pois tais narrativas teriam a mesma densidade dos romances: a voz narradora é o sujeito da memória, voz que não se localiza completamente num único sujeito.

Em As cidades invisíveis, texto escrito em 1972, Italo Calvino constroe, na voz narrante de Marco Polo, cidades que fariam parte do império do conquistador Kublai Khan, a partir, significativamente, de textos breves, e como nas cartas, crónicas e relações da colônia em América, estas cidades são reais através dos relatos. Mas estes, diferentemente dos relatos/informes em tempos de colônia no novo mundo, são muito breves. É interessante que a visibilidade destas cidades resida justamente no fragmento. Cada cidade é uma pequena narração, e no texto se nos deixa saber que não poderia ser de outra forma, como se percebe no seguinte trecho extraído do último relato do livro, "As cidades ocultas 5":

\begin{abstract}
Por esses portos seus não saberia traçar a rota nos mapas nem fixar a data da atracação. Às vezes basta-me uma partícula que se abre no meio de uma paisagem incongruente, um aflorar de luzes na neblina, o diálogo de dois passantes que se encontram no vaivém, para pensar que partindo dali construirei pedaço por pedaço a cidade perfeita, feita de fragmentos misturados com o resto, de instantes separados por intervalos, de sinais que alguém envia e não sabe quem capta. Se digo que a cidade para a qual tende a minha viagem é descontínua no espaço e no tempo, ora mais rala, ora mais densa, você não deve crer que pode parar de procurá-la. Pode ser que enquanto falamos ela esteja aflorando dispersa dentro dos confins de seu império; é possível encontra-la, mas da maneira que eu disse (CALVINO, 1990, p. 70).
\end{abstract}

Vemos o narrador apresentar cidades que só podem ser construídas a partir de um

\footnotetext{
${ }^{26}$ Campra é escritora e professora da Universidade de Roma 'La Sapienza', especialista em narrativa fantástica. Nascida em Córdoba-Argentina, atualmente mora na Itália.
} 
discurso fragmentado, pois elas são essencialmente isso: "fragmentos misturados com o resto, instantes separados por intervalos, descontínuos no espaço e o tempo...”. A literatura da América Latina, que desde a segunda década do século XX tem produzido e reproduzido discursos breves, fragmentados e descontínuos, cria um imaginário fantástico das cidades em contínuo movimento, de uma região que sempre esteve nos discursos da diferença, na tentativa de ser definida em relação ao velho mundo. Os rumos da microficção na América-Latina são vários, fragmentados na teoria, na ficção e na história; os rumores desta "máquina do pensamento" nos levam a repensar a natureza fantástica da linguagem, do texto, do arquivo e, com isso, da comunidade.

\section{REFERENCIAS BIBLIOGRÁFICAS.}

ARCINIEGAS, Triunfo. Noticias de la niebla. Medellín: Gato negro. 2010

BARROS, Pía. Llamadas perdidas. Barcelona: Thule ediciones. 2006.

BARTHES, Roland. O rumor da língua. São Paulo: Martins Fontes, 2004.

A câmara clara. Nota sobre a fotografia. Rio de Janeiro: Nova fronteira. 1984.

O prazer do texto. São Paulo: Perspectiva. 1987

BATAILLE, George. A literatura e o mal. Porto Alegre: L\&PM. 1989. . O erotismo. Porto Alegre: ed. LePM. 1987.

BLANCHOT, Maurice. -A leitura de Kafkall. Em A parte do fogo. Rio de Janeiro: Rocco. 2011 A conversa infinita. A palavra plural. São Paulo: Escuta. 2010.

A comunidade inconfessável. Brasília: Lumme. 2013.

—O narradorl Em: Obras escolhidas. São Paulo: Brasiliense. 1984.

BORGES, Jorge L, Outras inquisições. São Paulo: Companhia Das Letras. 2007.

BORGES, Jorge L; CASARES, Bioy. Cuentos breves y extraordinarios. Edición online. 1953. ; OCAMPO, Silvina. Antologia da literatura fantástica. São Paulo: Cosas Naife. 2013.

CALVINO, Italo. Seis propuestas para el próximo milenio. Madrid: Ciruela. 1994.

Diogo. 1990. As cidades invisíveis. São Paulo: Companhia das letras. Trad. Mainardi, 
CAMPRA, Rosalba. —Anaquel de microficciones\|, Letral, 2011, pp. 160-176.

CORTÁZAR, Julio. Obra crítica. Vol3. Rio de Janeiro: civilização brasileira, 2001.

Del cuento corto e sus alrededores. Em Ultimo raund.1969. Dispinovel:http://www.ciudadseva.com/textos/teoria/opin/del_cuento_b reve_y_sus_alrededores.htm. Texto sem paginação.

1999. Versão Digital.

Obra crítica 2. Organizada por Jaime Alazraki. Rio de Janeiro: Civilização Brasileira.

DI GERÓNIMO, Miriam. Narrar por knock-out. La poética del cuento de Julio Cortázar. Buenos Aires: Simurg. 2004.

DUARTE, De Andrade Pedro. Dois tempos da literatura: António Candido, Silviano Santiago e o modernismo. Revista Semear 8, s.d, s.p. Disponivel em: www. Letras.puc-rio.br

GÓMEZ DE LA SERNA, Ramón. Dispares y otros caprichos. Palencia: Menoscuarto. 2005.

LAGMANOVICH, David. El microrrelato. Teoría e historia. Palencia: Menoscuarto. 2006. Los cuatro elementos. Microrrelatos. Palencia: Menoscuarto. 2007.

LOPES, Denilson. Beleza, beleza e nada mais. Revista literária. Ilha do Desterro. N 51, p. 165 181. Jul/dez. 2006.

MARTINEZ; RODRIGUES. - Sobre o micro-conto no Brasill: Heloisa Buarque: A ascensão do micro-conto brasileiro no inicio do século XXI. Em Microcontos e outras microformas. Alguns ensaios. Rio de Janeiro: Universidade de Minha.

NOREGOL, Francisca. Espectrografias. Minificción e silencio. Em revista crítica de narrativa breve. N 3. 2011. Disponivel on-line http://lejana.elte.hu/PDF_3/Francisca\%20Noguerol.pdf.

ROAS, David. A ameaça do fantástico. Aproximações teóricas. São Paulo: Unesp. 2014. Poéticas del microrrelato. Compilación de textos. Madrid: Arco Libros. 2010. A ameaça do fantástico. São Paulo: Unesp. 2013.

RODRIGUEZ, Jaime. A. Curso de narratológia. Para el estúdio y disfrute de las narraciones. Bogotá: Pontificia universidad Javeriana. 2004, p. 10.

ROJO, Violeta. Breve manual (ampliado) para reconocer minicuentos. Caracas: equinoccio, 2009, p. 37.

SANTIAGO, Silviano. Uma literatura nos trópicos. Rio de Janeiro: Rocco. 2000. SCHOLLHAMMER, Karl Erik. Ficção brasileira contemporânea. Rio de Janeiro: Civilização brasileira. 2009.

SHUA, Ana María. Fenómenos de circo. Buenos Aires: Emecé. 2011.

La Suenera. Buenos Aires: Emecé. 2006.

TAMAYO, Martalucia. Germán Arciniegas y Macedonio Fernández: vidas paralelas 
posmodernas. Bogotá: Ed Pontificia Universidad javeriana. 2006.

TOMASSINI, Graciela. COLOMBO, Stella. La microficción como uma máquina de pensar. Revista electrónica de estúdios sobre la ficción breve. El cuento en red, p.31.

TREVISAN, Dalton. 111 ais. LP\&M Pocket. Brasil. 2000, p. 67

VALENZUELA, Laura. Em Brevs. Micorrelatos completos hasta hoy. Córdoba: Alcion. 2004.

VEJMELKA, Marcel. A ordem do mundo segundo João Gilberto Noll. Mínimos, múltiplos. Ver Ibero-americana. 2009.

Disponível: http://www.iai.spkberlin.de/fileadmin/dokumentenbibliothek/Iberoamericana/362009/36_Vejmel ka.pdf

ZAVALA, Lauro. La microficción bajo el microscopio. México, D.F: Difusión cultural UNAM. 2006.

Minificción contemporánea. La ficción ultracorta y la literatura posmoderna. Guanajuato: Universidad Autónoma de Guanajuato. Notas de curso. 2011. 